\title{
Balanço econômico-político de uma época histórica ${ }^{(*)}$
}

\section{Theotonio Monteiro de Barros Filho}

Alguns historiógrafos, criticando a divisão cronológica da História da Civilização, inclinam-se, de preferência, no sentido de ụma classificação dos períodos evolutivos da Humanidade, com base no tipo de cultura que caracterizou a cada um dêles. $O$ certo, porém, é que, em razão de uma conveniência mais didática do que científica, a divisão cronológica vem prevalecendo. $\mathrm{E}$ nos compêndios, a última era histórica surge sob a denominação de "época contemporânea", iniciando-se com a Revolução Francesa e vindo até nossos dias.

Entretanto, há cêrca de vinte e cinco anos, entrou essa época numa hora crepuscular, a que se seguiu escura noite, agitada pelo fragôr de lutas nunca dantes pelejadas. Desviada de uma róta que chegára a lhe parecer definitiva e segura, perturbada pela subversão das idéias e dos valores materiais e culturais, a Humanidade, entre dôres e incertezas, vem marcando um compasso de espera ritmado pelo rufar dos tambores e pelo troar dos canhões de duas guerras, até que deste novo "fiat" cultural desponte um outro dia, cuja aurora já se vislumbra. A "época contemporânea" passa a ser, na História, uma página virada. Será preciso dar-se-lhe um novo nome, uma vez que já está deixando de ser "contemporânea". Se a mim coubesse denominá-la, chamá-la-ia “A Idade Liberal-Capitalista".

(") Aula inaugural dos cursos da Faculdade de Direito da Universidade de São Paulo, proferida, a 28 de março de 1944. 
Fazendo em 1934 um ensaio sôbre "La Réforme de l'État", Georges Viance, no início do seu terceiro capítulo, escreve estas palavras:

"O espetáculo político do mundo atual é singular pela diversidade dos regimens desordenados que apresenta, como se todos os exemplos daquilo que convém evitar-se houvessem sido reunidos para nosso ensinamento prático".

E' a desorientação no campo da Política e da Ettica, acima de tudo. Mas, como que para aumentar a aflição ao aflito, como se não bastasse a guerra nem fossem suficientes as dificuldades políticas e sociais, também os teóricos da Economia, perplexos deante das surpresas encerradas pelos fatos, empenham-se acesamente na luta que divide liberaes e planificadores.

Estamos portanto, neste fim de período histórico, em um desses momentos que convidam os homens à meditação. Aqueles aos quais, pela situação e pelo saber, cabe a suprema honra e a pesada responsabilidade de exercitar função dirigente ou formadora, precisam ter repetidos intervalos de completa introversão, afim de que, pela reflexão desapaixonada e pela pesquiza científica dos fenomenos da hora mundial, possam efetivamente conduzir e orientar com a mais alta percentagem alcançavel de verdade e de segurança.

Urge que se faça, sem faciosismo nem ódios, um inventário da época findante e que cada um traga à colação o fruto de seus sinceros pensamentos, o seu esforço de bôa vontade para a grande genese do futuro. Sim, porque cessado o desencadeamento das forças irracionais da destruição, que a guerra infelizmente reclama, na hora de se reconstruir, o primado ha de ser do amor e da inteligência, sob pena de não se fazer obra duradoura.

(1) Georges Viance - "Préface a une Réforme de l'Etat". Paris. ๙/d. Edit. Desclée de Brouwer \& Cie. Pag. 101. 
Cerca de cento e cincoenta anos vem durando a chamada "época contemporânea". Foi, dos períodos históricos, o mais curto. Mas nem por isso terá sido, dentre eles, o que menor acervo legou.

De tal acervo, vamos fixar a parte que, numa preleção inaugural de estudos jurídicos, mais pode interessar: o Estado de Direito, que foi a sua mais peculiar creação. Uma recapitulação dos seus elementos, seguida da análise de cada um deles, indagando das transformações e das possibilidades de sobrevivência, será o nosso tema, cujo desenvolvimento procuraremos encerrar com um esforço no sentido de perscrutar o futuro.

\section{O ESTADO DE DIREITO}

Antes, porém, de prosseguirmos, convém que, por amor da clareza e da compreensão, precisemos um conceito. A expressão "Estado de Direito" usada pela primeira vez em 1832, no título da obra de von MoHL, "Die Polizeiwissenschaft den Grundsätzen des Rechtstaats", obra editada em Tübingen, provocou divergências e discussões, envolvendo inicialmente um conceito equivoco. Alguns a entenderam com um sentido puramente técnico e lógico-formal, enquanto outros procuraram o seu significado no conteúdo das idéias democráticas, liberais e individualistas que nortearam a estruturação dos Estados após a Revolução Francesa. Para os primeiros, sempre que o Estado exerça funções e realise fins dentro de um ordenamento cujas competências e cujos meios de ação se achem préviamente estabelecidos por normas jurídicas, estará caracterizado o Estado de Direito. Para os segundos, este se confunde com o Estado liberal-burguês, porque foi uma creação específica da burguezia, após a sua irrupção predominante na vida política, atravez da Revolução Francesa. Olhada a divergência por um prisma estrictamente técnico-juridico, os primeiros é que estão com a razão. Mas sob o ponto-de-vista histórico político também 
os segundos não estão errados. E sendo assim, fica-me livre hoje aqui, por amor da brevidade, o uso da expressão em seu sentido histórico-político, identificado o Estado de Direito com o liberal-burguês.

Isto posto, assentada a preliminar da existência de normas positivas vigentes, dentro das quais atuarão obrigatoriamente as competências, a análise nos revela, como elementos ligados especificamente aos Estados contemporâneos, até o início da primeira grande guerra, os seguintes: - no campo econômico: o liberalismo, como princípio informativo; - no campo jurídico-político: a democracia, como forma de govêrno, embóra alguns deles se houvessem conservado morfológicamente monárquicos.

Examinados sob um critério econômico, - é este o meu prisma de hoje, - procuremos discernir quaes as transformações sofridas por esses conceitos, desde a sua configuração inicial, no decorrer deste século e meio de evolução. Como se comportaram eles em face das injunções do meio? Que deformações se operaram em seu conteúdo? Que possibilidade ha de aproveitamento e de sobrevivência? Que reajustamento estão reclamando, para uma atualização? Até onde poderão ser atualizados, de acôrdo com as novas condições do mundo, sem perda de suas características específicas? Que repercussões poderão ter sôbre a estrutura jurídica e política de amanhã as modificações que, porventura, precisem ser feitas no conteúdo primitivo de taes conceitos?

Aí estão perguntas que desafiam a curiosidade de cada homem, nesta hora. Mas o problema não é sómente especulativo. Das conclusões a que se possa chegar, dependem, de um modo dreto, não só a felicidade do homem genéricamente considerado, mas também a de cada um individualmente.

Entremos na nossa análise.

\section{o LIBERALISMO}

Depois de haver estudado, no seu tempo, o processo da formação dos preços, atravez do funcionamento dos mer- 
cados, os clássicos do liberalismo chegaram à conclusão de que a melhor maneira de assegurar-se o desenvolvimento da atividade econômica consiste em deixar livre a iniciativa individual, atuando em regime de concurrência. Constitue esta última um fator de equilíbrio, um estímulo para o aperfeiçoamento, e uma garantia de elasticidade, condições essas: necessárias à boa saúde econômica. De fato, regulando automáticamente as quantidades em presença, quer de mercadorias, quer de serviços, atravez de um preço fixado pelo jogo da oferta e da procura, a concurrência promove o equilibrio, impedindo o prejuizo para produtores, trabalhadores e consumidores, a um só tempo. Faz, por outro lado, com que se apurem as mercadorias em qualidade, fomentando o progresso geral e, particularmente, o bem estar dos consumidores. Por sua vez, a procura, atuando de modo livre e combinando-se com o interêsse individual, faz com que a atividade econômica acompanhe fácil e plasticamente as va-riações dos gostos, desejos, necessidades da população.

Neste sistema ideal, construido com base no estudo e na observação da vida econômica da época em que foi formulado, a concurrência, posta ao lado do interesse individual, tinha um papel essencial. Ela era o único clima possível para o liberalismo. Sem ela todo o arcabouço se derrocaria.

Aconteceu, porém, que a doutrina econômica liberal, uma vez formulada, conservou-se estática. Ora, por seu lado, a sociedade, no campo econômico e nos demais, é essencialmente dinâmica. Em consequência desse dinamismo, as atividades agrícolas, comerciais e, notadamente, as industrias entraram a expandir-se num surto incoercivel. A sociedade industrializou-se, auxiliada pela máquina, numa progressão imprevista.

E então, nesse cenário econômico imensamente ampliado, vejamos como as coisas passaram a correr na prática. Livre o campo de luta, os interêsses particulares, atraídos: pelas mais diversas perspectivas de lucro, entraram em concurrência aberta. Em cada ramo da atividade econômica, as emprêsas mais bem condicionadas para a vitória, lo- 
graram expandir-se à custa das outras que o eram menos e que, por isso, desapareceram. Muito não tardou para que, em cada setor, a grande multiplicidade das emprêsas de pequeno porte viesse a ser substituida por um restrito número de emprêsas de grande porte. Mas aí não parou esse processo que estamos acompanhando. Postas umas em face das outras, estas grandes emprêsas concurrentes logo perceberam que não estava dentro dos seus interêsses a continuação de uma luta que acabaria por lhes restringir as possibilidades de lucro, ou mesmo por levá-las ao desaparecimento. E então chega-se ao último estádio de uma evolução que está comprovada pela experiência: a concurrência desaparece, para dar lugar ao estabelecimento de monopólios de fato, nos diversos setores da atividade econômica de tipo industrial, que é justamente a mais poderosa. (2)

Este fenômeno está estudado em todos os seus pormenores em qualquer livro de economia industrial. Realiza-se por diversos modos. Ora é a agregação conoentrica, que se verifica por accessão, quando uma emprêsa cresce ao redor de seu núcleo primitivo, sem grande alteração de seu caráter. Ora é aconsolidação horizontal, que se dá quando, sem modificação de material e de processos ou de produtos, diversas emprêsas industriais similares se combinam sob uma administração única. Ora, finalmente, o que se passa é a integração vertical "mediante a extensão do controle dos materiais e processos para traz até chegar às fontes de matéria prima, ou para a frente até lograr um controle em ambas as direções". (3) Há ainda um refinamento último dessas práticas avassaladoras, que, na economia norte- americana, aparece com o nome de "holding". O "holding" consiste no controle, por meio de ações e de uma supervisão centralizada, de várias emprêsas industriais, de ramos diversos, situadas numa mesma localidade ou em pontos dife-

(2) Gaetan Pirou - "Néo-liberalisme. Néo-corporatisme. Néo-socialisme". 2. a ed. Editor Galimard. Paris, 1939. Pgs. 13 e segs.

(3) Dexter S. Krmball - "Economia Industrial". Ed. do Fondo de Cultura Econômica. México, 1942. Pags. 164-165. 
rentes, conservando cada uma delas a sua autonomia contabil. (4)

Este processo desenvolve-se invariavelmente nos grandes países industrializados, e aparece com maior ou menor intensidade, mas surge sempre em toda parte. O seu desfecho é, como se vê, a eliminação final da concurrência e, portanto, a supressão de uma das condições essenciais de qualquer estrutura econômica de base liberal. Ao formular a sua doutrina, os clássicos do liberalismo tinham estado em face apenas de uma industrialização incipiente. Conheciam o capital e sabiam ser ele um fator da produção. Mas não tinham tido o ensejo de observar os grandes volumes capitalistas, desconhecendo, na época, essa tendência imanente do capital para a concentração.

Ora, uma tal tendência encontra no Direito Privado de todos os povos civilizados atuais um magnífico instrumento de realização, cuja eficiência os liberais clássicos não tinham podido medir: é a sociedade anônima. Ninguém desconhece os altos méritos desse instituto jurídico, nem é nosso intuito aqui dissentir das lôas que lhe vêm cantadas por juristas e mesmo economistas (5). Sem dúvida ela tem sido um instrumento de progresso em muitos sentidos;' $E^{\prime}$ certo também que do ponto-de-vista social, ela possibilita o aproveitamento de grandes potenciaes de trabalho, atenuando, atravez de enormes iniciativas, os efeitos daninhos do desemprego. Mas focalizada objetivamente, sob o prisma econômico, a sociedade anônima é o maior agente da concentração de capital, graças ao seu extenso e flexivel poder coletor de reservas monetárias poupadas pelos particulares.

Aí fica, analisada em largos e objetivos traços, com base experimental, a contradição íntima que vive nas entranhas do liberalismo clássico: ele não existe sem a concurrência; mas a concurrência levou a economia contemporânea ao ca-

(4) Dexter S. Krmball - op. cit., pg. 165. - G. Pirou, op. cit. pgs. 33-34.

(5) Bertrand Nogaro - “Elements d'Economie Politique". Ed. Librarie Delagrave. Paris, 1936, 4.* ed. Pgs. 24-25. 
pitalismo; o capital, concentrado, por força de uma tendência que lhe é imanente, elimina a concurrência.

Essa não é, contudo, a única consequência do desenvolvimento do capitalismo, que se apresenta como contrária aos fundamentos da doutrina liberal. Gaetan Pirou, a quem em mais de um passo tomei subsidios para este apanhado do liberalismo, aponta uma outra situação, muito comum na prática, em que se evidencia o desajustamento do liberalismo econômico clássico com os fatos atuais, e até mesmo um resultado de algum modo injusto. E' o caso de certas grandes emprêsas, em épocas de depressão econômica. Representando enormes interêsses materiais, englobando inúmeras pequenas economias de particulares, estabelecendo em torno de si uma intensa trama de relações jurídicas e sociais, empregando a um grande número de trabalhadores, frequentemente acontece que alguma delas ameaça ruir. Mas tal seria a repercussão da québra ou do desaparecimento, que o Estado se vê forçado a intervir em socorro, acudindo economicamente até que se restabeleça o equilíbrio, embóra para isso tenha, às vezes, de fazer pesados sacrifícios. Ora, essa interferência do Estado, mesmo para socorrer, é um desmentido aos princípios liberais. Por outro lado, ela envolve uma consequência injusta, porque deixa individualizados os lucros das épocas de prosperidade, enquanto que socializa os prejuizos dos periodos de crise.

Não será preciso ir alem para demonstrar que o liberalismo econômico clássico está reclamando uma revisão sevéra, se quizer sobreviver. Confessam-no os próprios liberais, quando, de uns poucos anos a esta parte, vêm fazendo públicamente esforços reajustadores de sua doutrina. Na França e nos Estados Unidos, nos últimos dias que precederam a guerra atual, esboçou-se com vivacidade o movimento a que se deu o nome de néo-liberalismo. A ele aludirei mais adeante, noutro tópico desta aula.

Por agora, a bem do roteiro que me propuz, vamos passar alem. Conservando sempre o ponto-de-vista nitidamen- 
te econômico, que de início adotei, examinemos o segundo elemento do Estado de Direito liberal: a democracia.

\section{A DEMOCRACIA}

Tendo o Estado de Direito liberal, que estamos estudando, sido estruturado, desde o seu advento, em bases democráticas, a primeira questão a indagar, do ponto-de-vista econômico, é se os conceitos de liberalismo e de democracia apresentam entre si uma ligação tão essencial, que os obrigue a uma realização prática sempre geminada.

Bem se compreende o alcance do problema. Se à forma clássica do liberalismo econômico pódem ser opostas, no momento atual, sérias objeções resultantes da sua inadaptação à realidade vigente, e se o liberalismo houvesse de ser considerado como o único clima próprio da democracia, então haveriamos de concluir fazendo reservas tambérn a esta última.

Entretanto, não nos parece que seja esse o caso.

Olhado do prisma econômico, o liberalismo repousa na combinação de dois principios: o do interêsse individual, e o da livre concurrência. Para assegurar a efetividade desta última, preconiza a não intervenção do Estado. No fundo, é na rejeição de qualquer forma de intervencionismo que reside a essência da doutrina liberal. Não é só a intervenção no campo econômico que ela repele, pois também não tolera interferência estatal direta no campo intelectual e no político. Não é possível, entretanto, confundir o liberalismo econômico, que ainda há pouco analisámos, com as suas outras formas: o liberalismo político e o intelectual. Assim, ainda que a realização prática da democracia encontrasse melhores condições quando ligada a um liberalismo intelectual e político, - o que seria uma tése a examinar-se, — nem por isso impor-se-ia como necessário o liberalismo econômico, que é coisa bem diferente. Demais, não é exato que a idẻia de liberdade constitủa um todo absoluto, que só 
possa ser aceito ou rejeitado em blóco. Não posso furtar-me aqui à citação de uma passagem grandemente ilustrativa de Gaetan Pirov. Depois de observar, algumas páginas antes, que os néo-liberais da França procuram englobar habilmente às diversas modalidades do liberalismo, afim de levarem os franceses, sempre ciosos da sua liberdade política e intelectual, a aceitar também o liberalismo econômico, diz ele:

"Consideremos, enfim, o laço que pretendem estabelecer os néo-liberais entre o liberalismo econômico e a democracia. Aí ainda a sua posição se choca com certas objeções graves. Um dos adversários do néo-liberalismo (que é ao mesmo tempc um dos teóricos mais representativos da economia planificada e que a esse título tornaremos a encontrar), o snr. Marcel Deat, não perde a ocasião de assinalar a existência de algo de sofístico, ao querer-se assimilar o liberalismo econômico ao intelectual e ao político. Na verdade, para quem está de fato interessado pela liberdade de opinião e pelo funcionamento correto da democracia, parece difícil não ser levado a admitir que a liberdade econômica deva ser vigiada e limitada, quando ela põe em perigo as outras formas, singularmente mais respeitáveis, da liberdade. Evoquemos uma última vez esse processo econômico que ha pouco tracejamos. Se é certo que a liberdade econômica engendra o grande capitalismo, e se o poder deste, quando não é severamente controlado, arneaça falsear as engrenagens da democracia, ha de se admitir que é lógico, para um democrata, ter alguma desconfiança em relação aó liberalismo econômico integral. Demais, basta evocar as admiráveis mensagens do Presidente Roosevelt para nos convencermos de que o mesmo homem póde ser, a só tempo (e sem nenhuma contradição), o apos- 
tolo mais eloquente da liberdade de conciência e da democracia, que hoje ha no mundo, e também o iniciador da maior experiência de economia dirigida no quadro do capitalismo. Admitido isto, concluir-se-á que um espírito livre e um democrata não são de nenhum modo obrigados, em matéria econômica, a ser liberais. Todavia, se eles se inclinam para o dirigismo, deverão ter em vista que numa democracia o dirigismo é mais difícil, arrisca-se a ser menos eficaz e deve ser mais moderado do que num regime totalitário".

Arturo Enrique Sampay, nesta mesma ordem de idéias, recorda haver a democracia conhecido realizações anti-liberais, e afirma:

"A síntese aleatória da democracia e do liberalismo é uma contingência histórica, e se explica pela circunstância de terem sido obrigados a combater um inimigo comum: - o Estado absoluto".

Esta afirmativa do ilustre escritor, membro destacado do Instituto Argentino de Filosofia Juridica e Social, bem se justifica, na verdade. Nos albores do século XVII, estava formada na Europa uma mentalidade tomada pelo espírito de empreendimento e de acumulação de riquezas, condicionada pelo pensamento renascentista e pela quebra de rigidez da tradição católica, consequente à Reforma. Sobrestimavam-se os valores materiais e aguçavam-se as múltiplas formas de cobiça mundana. O velho "tiers état", oprimido pelo absolutismo, tornava-se fortemente reivindicante, como se vê da formula de Sieyès: "Que é o terceiro estado? Tudo. - Que foi até agóra na ordem política? Nada. - Que é o

(6) Gaetan Pirou - op. cit., pgs, 55-57.

(7) Arturo Enrique Sampay - "La crisis del Estado de Derecho liberal-burguêts". Edit. Losada S. A. Buenos Aires, s/d Pg. 84. 
que pede? Tornar-se alguma coisa". Assim, quando por obra e arte da Revolução Francesa, esse terceiro estado entrou vitorioso na arena da vida pública, trazia, alem dos recalques resultantes de uma velha opressão sofrida, uma atitude desconfiada em relação à soma de poderes do Estado. Ao ser este organizado democraticamente, o Liberalismo, a serviço da nova e vitoriosa classe, tratou de assegurar as liberdades, não atravez de uma série de afirmativas ligadas a direitos subjetivos inerentes ao homem, mas apenas por meio de um conjunto de negativas opostas à ação do Estado. Nasceram assim as Declarações dos Direitos do Homem. A liberdade perdia a grande dignidade que o Direito Natural lhe emprestava, passando a ser uma méra expressão formal. E a Economia, já a essa altura libertada de t́tica, foi objeto de especial cuidado, no sentido de deixá-la fóra do alcance policiador do Estado, afim de que a cupidez se pudesse exercer sem entraves, nem restrições. Para consegui-lo instituíu-se formalmente a "liberdade econômica".

Aduzo agora argumento em favor da tése, que sustento, de que a democracia póde e até deve organizar-se fóra do âmbito do liberalismo econômico. E' um argumento de autoridade, mas da mais insuspeita das autoridades: Francesco Nitri. NirTi, o grande democrata, também o aceita e o sustenta. Para ele, qualquer regime econômico se compadece com a fórma democrática de govêrno, desde que a sua adoção resulte de uma livre deliberação da soberania. (8)

$\mathrm{E}$ como remate a estas considerações, envio os meus ouvintes aos Anaes da "American Academy of Political and Social Science", especialmente para o volume de 1938, onde se encontra uma longa e proveitosa série de estudos sôbre as diversas formas pelas quais as liberdades vêm sendo restringidas na grande republica norte-americana por ação do capitalismo. Um desses estudos, particularmente ilustrativo para o meu ponto-de-vista, documenta com fatos as interfe-

(8) Francesco NitTi - "La Democrazia" - Editions Contemporaines. Paris, 1932. vol. II, pg. 419. 
rências do poderio econômico, como força desvirtuadora até mesmo da liberdade de cátedra. (9)

Pensamos, portanto, que apezar da divergência reinante no mundo atual entre liberais e planificadores, a democracia sobreviverá fortalecida e solidificada, como a forma de govêrno mais consentânea com as verdadeiras liberdades e com a dignidade da pessôa humana. A crise não é da democracia. Esta está até mesmo dando, neste momento, ua guerra, uma grande demonstração de vitalidade. Não pressinto que, da necessidade de se limitar e policiar a atividade econômico-privada, haja de resultar lesão para as outras liberdades do homem, que - essas sim - precisam ser resguardadas, porque sobrepairam à materialidade da vida. Ao contrário: parece-me que a evolução ha de resultar bem e para melhor.

Com isto não quero dizer que a própria democracia não esteja carecendo de atualizar alguns de seus institutos e de modificar certos de seus processos.

A sociedade intensamente industrializada em que vivemos alterou diversos dados do problema democrático. De 1850 a 1933, isto é, em menos de cem anos, a população do globo passou de um bilhão cento e setenta e um milhões para dois bilhões e cincoenta e sete milhões. Paralelamente com esse formidável aumento, o fenomeno da urbanização das populações se manifesta por toda parte. Crescem incessantemente os centros industriais e cada dia um maior número de individuos vae sendo aplicado nas atividades fabrís. Como se sabe, essas atividades se desenvolvem atravez de uma técnica funcionalmente racionalizada. Ora, a racionalização funcional, segundo afirmam sociólogos e psicólogos, não parece ser muito favorável ao desenvolvimento concomitante da racionalização essencial, que é o tipo superior de racionalização, ou seja $a$ do pensamento. Á medida que o homem se racionaliza funcionalmente, desenvolvendo as

(9) The Annals of the American Academy of Political and Social Science. 1938. 
suas aptidões instintivas e reflexas, tende a diminuir-se, sob certos aspectos, notadamente sob o ponto-de-vista intelectual, habituando-se a não utilizar as suas faculdades de deliberar e de se dirigir, porque se acostuma a ser dirigido e a ter sempre quem delibere em seu lugar. Originam-se assim grandes massas humanas, que tendem a se lançar cada vez mais na vida pública, sôbre a qual procuram influir. Mas essas massas diferem fundamentalmente do antigo conceito de "povo", a que estavamos habituados até agóra, no regimen democrático. Dentro da população de' um País, o "povo" constituia grupo político propriamente dito, sendo integrado por aqueles indivíduos que, em virtude da pósse de requisitos legais mínimos de cultura e de situação econômica, eram considerados aptos ao exercício da cidadania e do voto. Hoje a tendência crecente é a da participação de todos na coisa pública, agindo massiçamente, em ação diréta, frequentemente impulsiva e violenta, - ação de massas essa que também é constante, ao contrário das interferências do "povo" na vida pública anterior, que se caracterizavam pela sua intermitência, restringindo-se aos momentos dos pleitos eleitorais. E' preciso, portanto, que a democracia cogite sériamente do encontro de novas técnicas, quer jurídicas, quer sociais, para a captação ordenada e pacífica da vontade e das inclinações das massas. O Direito Eleitoral, nos países. democráticos, principalmente naqueles mais fortemente industrializados, precisa de ser revisto e ajustado a estas novas realidades. Processos novos de propaganda e de orientação precisam ser aplicados. As massas, que agem mais. pelo instinto e pela intuição, do que pelo raciocínio, póden ser conduzidas a resultados inconvenientes e indesejáveis, quando postas sob a ação de uma mística. O nazismo nasceu do mito da superioridade racial, conjugado com a exploração demagógica do instinto de vingança. O fascismo proveio da absolutização do conceito político e moral de Nação. O sovietismo comunista só foi possível, graças á creação do mito da superioridade da classe proletária sôbre todas as 
demais, mito esse articulado com a exploração psicológica de velhos complexos do povo russo.

Se as nações democráticas desejam realmente sobreviver como tais, preservando a liberdade, e fugindo a estas deformações morbidas, ser-lhes-á necessário adotar também a sua propaganda. De novas místicas não carecem elas. A liberdade tem, por si só, para os homens, um forte poder de sedução e de proselitismo. Mas contra a má propaganda, aproveite-se a maleabilidade e o instinto livre das massas, atravez da bôa propaganda, que haja de fortálecer a democracia. Não tenhamos mêdo das palavras. Ainda ha pouco, Bartlett, professor da Universidade de Cambridge, publicou um estudo em que defende a necessidade da propaganda política técnicamente organizada, dando dela a noção seguinte: "a propaganda tem o propósito de influir na opinião e na conduta, especialmente na opinião e conduta sociais, de modo a que os indivíduos adótem opiniões e condutas indicadas sem que para isso realizem uma busca definitiva de razões" (10). Aí está como a velha e livre Inglaterra, exemplarmente democrática, se prepara para rejuvenescer os seus métodos.

Toda esta seára, porém, é estranha ás cogitações do economista e do financista. Fica a outros o seu estudo pormenorizado e o encontro das bôas soluções. E' certo, entretanto, que, pesquizando os reflexos das modificações do meio econômico e social sôbre a democracia, não poderiamos deixar de aludir a tais problemas nesta aula, ainda que de passagem.

\section{ONDE AS DOUTRINAS SE ENCONTRAM}

Caberá, então, na democracia um regime econômico planificado? Haverá um terreno comum, onde planificadores e até mesmo liberais se possam encontrar?

(10) F. C. Bartiett - "La Propaganda política". Ed. do Fondo de Cultura Econômica. México, 1941. Pg. 15. 
Dois grandes livros, de publicação relativamente recente deixam entrevêr que o dissídio ideológico entre liberais e os que sustentam a necessidade da limitação da liberdade econômica, conhecidos sob o rótulo geral de planificadores, caminha para alguns pontos de contato, que tendem a acentuar-se. Penso mesmo não ser muito otimista, ao considerar possivel que as duas correntes venham a encontrar aquele terreno comum, que representará uma média de opiniões. A Humanidade é uma grande realizadora de médias. E quando as lutas de idéias a afétam de um módo diréto na sua segurança, na sua liberdade ou no seu bem estar, ela sabe sempre retirar de cada campo a parte aproveitável para uma realização prática de caráter eclético.

O primeiro desses livros a que me refiro é "La Cité Libre", da autoria de Walter Lippmann, um liberal. Dando provas de possuir ainda uma aproveitável vitalidade, o liberalismo esforça-se no sentido da renovação, numa corrente que se intitula de "néo-liberalismo". A edição inglesa da obra de LippManN, sob o titulo "The good society", foi imediatamente traduzida em França, recebendo um prefácio ntusiástico de ANDrÉ MAURors, e provocando uma simpática repercussão na imprensa francesa. Coincidindo o aparecimento do livro e de sua tradução com uma viagem do autor á França, houve mesmo reuniões de economistas, com o propósito de iniciar-se o trabalho da revisão ideológica do liberalismo. Na própria França, já Louis Rougier, um economista francês, havia encetado esforço no mesmo sentido. Das reuniões nasceu o Centro Internacional de Estudos para a Renovação do Liberalismo. Como se vê, ha um grande impulso inicial de readaptação.

Qual o sentido dessa renovação? WaLter Lippmann, depois de estudar os exageros do capitalismo, que levaram a abalar-se o princípio da concurrência, chega a uma conclusão devéras interessante: o liberalismo estaria em crise, porque teria deixado de ser liberal. Se o capitalismo, que, na opinião do autor, é uma deformação do liberalismo, não houvesse tendido a dificultar e a eliminar a livre concur- 
rência, o liberalismo aí estaria sempre novo, sempre integro, sempre verdadeiro. Mas então, como corrigir-se o mal? $\mathrm{E}$ é na resposta a esta pergunta que vem a grande surpresa. E' preciso, preconiza LippmanN, que o Estado intervenha em certos setores da Economia, para coibir os abusos e os excessos, restaurando as possibilidades do funcionamento da livre concurrência. No seu capítulo intitulado "A agenda do Liberalismo", tive o cuidado de anotar nada menos de treze pontos em que é reclamada a interferência saneadora do Estado, abrangendo a produção, a circulação e até a moéda, que LIPPMANN desejaria vêr dirigida, afim de faze-la neutra, ou seja, não sujeita ao fenômeno das oscilações de valor. No campo financeiro, não trepida em aconselhar a aplicação de imposições fortemente progressivas, com o fito de facilitar o processo de desconcentração do capital. (11).

$O$ outro livro, dos dois a que ha pouco aludí, é da autoria de Karl Mannheim e se intitula "Libertad y Planificacion". Publicado inicialmente em 1935, foi vertido para o inglês em 1940 e teve tradução hespanhola em 1942. (12). KARL MANNHEIM, que vivera na Alemanha e sofrera em pessôa os ef eitos violentos das mudanças econômicas e sociais dos últimos tempos, chegára á conclusão de que não havia outro remédio senão a planificação. Antes, porém, de sair a lume a edição inglesa de sua obra, as circunstâncias o levaram a ter de viver na Inglaterra e a assistir ali aquilo que julgára quasi o impossível, isto é, o funcionamento util do liberalismo. E, portanto, um homem que viveu sucessivamente as duas experiências diferentes. Daí o ser particularmente ilustrativa a sua leitura. Depois de afirmar que as suas inclinações pessoais são no sentido da liberdade (pg. 10-11), acrescenta, entretanto, que hoje não é mais possível a escolha entre o plano e o velho "laissez faire". Só ha a escolher entre a bôa e a má planificação (pg. 12). Mas uma

(11) Walter Lippman'N - "La Cité Libre",. Ed Librarie de Médicis. Paris, 1938. pgs. 245 e segs.

(12) Karl ManNHeIM - "Libertad y Planificacion". Ed. do Fondo de Cultura Econômica. México, 1942. Páginas citadas no texto. 
planificação que se destine não ao conformismo e sim á liberdade (pg. 229).

Depois de um exame germanicamente profundo das mudanças radicais operadas no campo econômico, bem como no social, afirma que "a maior parte dos sintomas do nosso tempo é devida à passagem que se está operando do laissez faire para uma sociedade planificada; "que a passagem da democracia minoritária para uma sociedade de massas explica outra série de perturbações", e, finalmente, "que as modificações na técnica social são a causa de um terceiro grupo de mudanças que alteram profundamente a nossa vida social" (pg. 227). Critica a intervenção desordenada do Estado e, a certa altura, acrescenta:

“Na natureza da planificação e do mecanismo democrático não há nada que os faça incompatíveis. O sistema parlamentar democrático elaborou um método para a concentração da soberania que o combina com a idéia do controle público. Por isto, a tática mais prudente para a democracia e para os defensores da liberdade seria, não a de oporem-se á planificação, mas a de crearem um tipo de planificação em que o controle democrático pudesse conservar-se, mediante garantias institucionais. Isto não se póde realizar mediante a fórmula antiquada do "laissez faire", mas só mediante uma direção cada vez mais conciente das técnicas, com o propósito de crear e conservar espaço para a liberdade e a auto-determinação, dentro dos marcos do plano" (pg. 308).

Ora, do confronto destas duas obras fundamentais, uma do liberalismo renovado e outra da planificação, resulta a presença, nos dois autores, de uma preocupação insistente acerca da personalidade humana e da auto-determinação, ou seja, da liberdade. O liberal Walter LipPManN transige em pontos de sua doutrina, para salvar a liberdade, atravez 
da restauração da concurrência. KARL MANnheim céde nas suas conclusões, para aceitar abertamente que a planificação nunca póssa ser para o conformismo e sim para a liberdade, e ainda para afirmar a necessidade de qualquer plano deixar espaço à liberdade, podendo sempre encartar-se no regime democrático.

Aí está esboçado o terreno comum em que as doutrinas começam a pisar. Conforta verificar que esse terreno é o da Liberdade e o do resguardo da personalidade. Tudo mais é questão de medida, que a continuação do estudo e as tentativas práticas de realização irão completando e aperfeiçoando. Mas desde que um tal ponto de contato esteja estabelecido no pensamento dos doutrinadores, póde-se a justo título ser otimista, quanto ao resultado último. $\mathrm{Na}$ preocupação de ambos os grupos, o que se encontra é um valor superior, que transcende das contingências materiais da vida econômica, mas que precisa, em seu próprio bem, ser resguardado por uma disciplina e por uma autoridade, que estão no Estado.

Chegada que seja a paz, não serão só as outras formas da liberdade que hão de encontrar a sua consagração. Também a liberdade econômica encontrará, por certo, aquele ponto de equilíbrio em que os direitos fundamentaes da creatura se póssam casar com os deveres dela para com a coletividade, e tambem com a necessaria obediencia à autoridade. Mais uma vez a Humanidade, desprezando as demasias teóricas dos dois lados, há de saber realizar a média, a sábia média. 